\title{
Retaining of Frequency in Micro-grid with Wind Turbine and Diesel Generator
}

\author{
Phan Dinh Chung \\ Faculty of Electrical Engineering, \\ The University of Danang-University of Science and Technology, \\ Danang, Vietnam \\ pdchung@dut.udn.vn
}

\begin{abstract}
This paper aims to compare the performance of frequency regulation with two control modes of controller including power control scheme and rotor speed control scheme. The frequency control in this research is based on the frequency droop control method but fuzzy logic is used to define the frequency droop coefficient. To compare the performance of these control modes, a simulation of a micro-grid with the existence of a group of doubly fed induction generator wind turbine system and a diesel generator is fulfilled in Matlab/Simulink. Simulation results indicated that the frequency in the micro-grid with two control schemes always remains in the operation range. With the power control scheme, the frequency in the micro-grid is smoother than that with the rotor speed control. Additionally, DFIG wind turbine with the power control scheme has a better performance in terms of electrical energy when compared to the rotor speed control scheme, and hence the cost of fuel used by diesel is less costly.
\end{abstract}

Keywords-wind generation; frequency control; doubly-fed induction generator (DFIG); wind-diesel hybrid power system; micro-grid

\section{INTRODUCTION}

Clean and renewable energy sources such as wind energy, solar energy, geothermal energy, etc. are abundant. These sources have been utilized to replace fossil energy sources which have negative impacts on the environment. Recently, the electricity production from these sources has been prospective, especially from the wind source. According to [1] around $540 \mathrm{GW}$ of wind turbine capacity has been installed. Depending on the wind farm capacity, a wind farm can be integrated to a power system through transmission grid or distribution grid [2, 3]. It cannot be denied that electricity generation from wind energy has a positive effect to the environment. However, the integration of wind farms to a power grid brings issues concerning power quality [2] due to the natural fluctuation of wind speed, especially in weak grids [4]. Many researches aimed to mitigate the wind farm's impacts on the connected grid. A simple solution is to install an energy storage system such as battery, super capacitor, super inductor, fly-wheel, pump-reservoir system, etc., to stabilize the power output of the wind turbine-generator system $[5,6]$. These schemes have good performance, however, the storage system in general is still quite expensive and has low life expectancy so it may face problems in real life applications.
For a weak power grid without a battery energy storage system, some methods to support the frequency adjustment were proposed in [2, 7-10]. Generally, reference power is defined by two components. The first component is a deloaded power calculated from wind speed signal and a deloaded power coefficient. The second component is power contribution by frequency sensitive supplementary control. For the second component, many schemes were used. In [9], a fuzzy-based control is employed to determine it directly. In $[2,7,8]$, the droop control method with a constant droop coefficient is used. In [9], authors used a combination of droop control and inertia control but the droop coefficient is defined by a fuzzy-based control and in [10], authors used wind speed as an input signal of the fuzzy logic control.

In terms of control objective applying to wind turbine, there are two familiar control objectives: power control and rotor speed control [11]. In [11], authors indicated that with the rotor speed control, the wind turbine has a better performance than that with the power control. Regarding wind turbine supporting frequency adjustment, wind turbine with the power control was studied in $[12,13]$ while the wind turbine with the rotor control was studied in [14]. However, the performance of these two control schemes in the frequency control has not yet been compared.

In this paper, the performances of frequency regulation method with two control modes of controller, power control and rotor speed control, are compared. The frequency control scheme in this research is developed from the frequency droop control method but a fuzzy logic rule is used to define the frequency droop coefficient. The wind turbine with power control will be compared to the one with rotor control by simulating a micro-grid with the existence of a group of doubly fed induction generators wind turbine system and a diesel generator. The current research consists of two contributions. The first contribution is the method to define the reference power/rotor speed. To determine the reference power/rotor speed, a wind speed sensor is not required. The second one is a comparison of the two control modes of the wind turbine when it participates in the frequency adjustment. The saturation of the magnetic core in equipment, the delay of measurement signal, and the measurement noise are neglected. 


\section{MICRO-GRID}

Micro-grid in this research is supposed to have the form of Figure 1 . This micro-grid is normally connected to the power system via a circuit breaker (CB). When the micro-grid is isolated from the power system, the micro-grid must retain its operation thanks to two electrical sources, including a diesel generator (or a small hydro power plant) and a doubly fed induction generator (DFIG) wind turbine group, to supply three loads. We suppose that Load 3 is an important and constant load while Load 1 and Load 2 are variable loads.

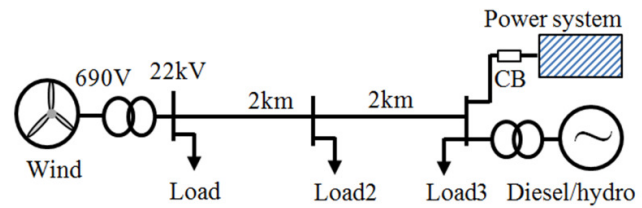

Fig. 1. The configuration of micro-grid.

\section{A. Wind Turbine}

A DFIG wind turbine consists of a blade system, a shaftgearbox, and a DFIG [15], as shown in Figure 2(a). The main duty of the blade system is to convert the wind's kinetic energy to mechanical energy on the turbine's shaft and then this mechanical energy is converted to electrical energy by the generator. The turbine's shaft and the generator one are coupled through a gearbox system. At wind speed $\mathrm{V}_{\mathrm{w}}(\mathrm{m} / \mathrm{s})$ and wind turbine's rotational velocity $\omega_{M}(\mathrm{rad} / \mathrm{s})$, the mechanical power on the turbine's shaft is computed as [16]:

$$
P_{M}(t)=\frac{1}{2} \rho \pi R^{2} C_{p}(\lambda, \beta) V_{w}^{3}(t)
$$

where, $\rho$ is the air density $(\mathrm{kg} / \mathrm{m} 3), R$ the length of the blade (m), $V_{w}$ is the wind speed $(\mathrm{m} / \mathrm{s})$, and $C_{p}(\lambda, \beta)$ is the power coefficient of wind turbine, which depends on both tip-speed ratio $\lambda$ and pitch angle $\beta$ of the wind turbine. According to [16], the tip-speed ratio is defined by:

$$
\lambda(t)=\frac{\omega_{M}(t) R}{V_{w}(t)}
$$

For wind turbine, $C_{p}(\lambda, \beta)$ has a unique maximum value $C_{\text {pmax }}$ at $\lambda=\lambda_{\text {opt }}$ as $\beta=0$. Hence, if the wind turbine operates at $\lambda_{\text {opt }}, P_{M}$ will be maximum.

$$
P_{\text {Mmax }}(t)=\frac{1}{2} \rho \pi R^{2} C_{\text {pmax }} V_{w}^{3}=\frac{1}{2} \rho \pi R^{5} \frac{C_{p \max }}{\lambda_{\text {opt }}^{3}} \omega_{\text {Mopt }}^{3}(t)
$$

where, we used (2) as

$$
\lambda_{\text {opt }}=\frac{\omega_{M o p t}(t) R}{V_{w}(t)} .
$$

The locus of maximum points or maximum power point tracking curve (MPPT curve) can be defined by:

$$
\begin{aligned}
& P_{\text {mppt }}\left(\omega_{M}\right)=k_{\text {opt }} \omega_{M}^{3}, \\
& k_{o p t} \triangleq \frac{1}{2} \rho \pi R^{5} \frac{C_{p m a x}}{\lambda_{o p t}^{3}} .
\end{aligned}
$$

The characteristic of the wind turbine, in the pu unit system, is shown in Figure 2(b). (a)

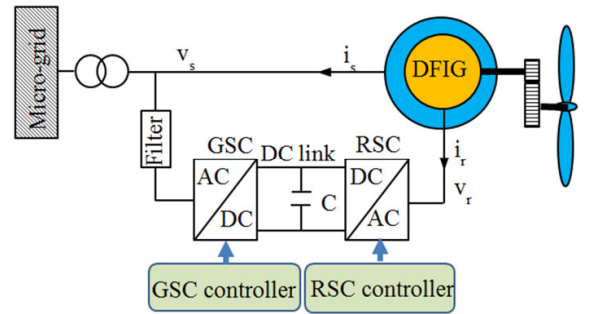

(b)

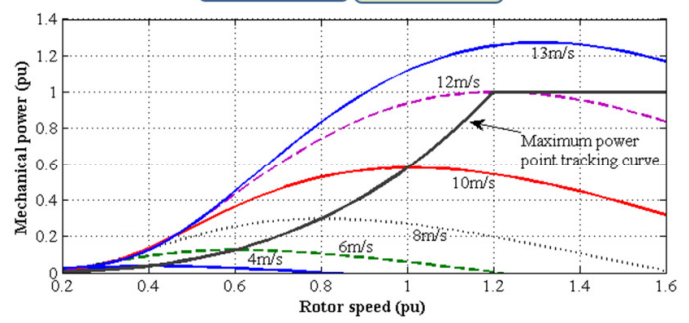

Fig. 2. Wind turbine system: (a) configuration of DFIG wind turbine, and (b) wind turbine characteristic.

For the wind turbine to operate on the MPPT curve, the rotational speed of the wind turbine must be calculated as in (4) or the mechanical power must be remained as in (3). In the case of wind sensorless control, we cannot determine the maximum power from (3) or the optimal rotor speed from (4) and hence, we must use the MPPT curve and the feedback power output (or the feedback rotor speed) to determine the optimal rotor speed (or the maximum power).

\section{B. Doubly Fed Induction Generator}

In this research, the wind turbine employs a DFIG to operate in variable speed as in Figure 2(a). DFIG is an induction generator, where the rotor windings are supplied through a partial back-to-back converter including a rotor side converter (RSC), a grid side converter (GSC) and a DC link [2, $17,18]$. Thanks to the back-to-back converter, the DFIG wind turbine can provide good control ability [19] to meet the operator's requirements. In this micro-grid, thanks to this ability, the DFIG wind turbine can support the diesel generator to retain the frequency in the normal operation range. The statespace equation of a DFIG in $d q$ frame, where $d$ axis is aligned with the stator flux vector, is described as [20]:

$$
\frac{d}{d t} \boldsymbol{i}_{r}(t)=\boldsymbol{A}_{r}(t) \boldsymbol{i}_{r}(t)+\boldsymbol{B}_{r} \boldsymbol{v}_{r}(t)+\boldsymbol{c}_{r}(t)
$$

where,

$$
\begin{aligned}
& \boldsymbol{A}_{r}(t)=-\frac{R_{r}}{\sigma} \boldsymbol{I}_{2}-\omega_{s}(t) \boldsymbol{\Theta}, \boldsymbol{B}_{r}=\frac{1}{\sigma} \boldsymbol{I}_{2}, \\
& \boldsymbol{C}_{r}(t)=\frac{V_{s} L_{m}}{L_{s}} s(t)\left[\begin{array}{l}
0 \\
1
\end{array}\right]-\omega_{\mathrm{M}} \boldsymbol{\Theta} \boldsymbol{i}_{r}(t), \boldsymbol{\Theta}=\left[\begin{array}{cc}
0 & -1 \\
1 & 0
\end{array}\right], \\
& \sigma=L_{r}-\frac{L_{m}^{2}}{L_{s}},(t)=1-\frac{\omega_{\mathrm{M}}(t)}{\omega_{\mathrm{S}}(t)},
\end{aligned}
$$

where: $\boldsymbol{i}_{r}=\left[\begin{array}{ll}i_{r d} & i_{r q}\end{array}\right]^{T}$ is the current in the rotor side, $\boldsymbol{v}_{r}=\left[\begin{array}{ll}v_{r d} & v_{r q}\end{array}\right]^{T}$ is the voltage in the rotor side, $L_{s}, L_{r}, L_{m}$ are the inductance of the stator winding, rotor winding and mutual, $R_{r}$ is the resistance of the rotor winding, and $\omega_{\mathrm{s}}, \omega_{\mathrm{M}}$ are the rotational speeds of the stator flux and rotor.

For the DFIG wind turbine without power losses, we have: 


$$
\begin{aligned}
& P_{M}(t)=(1-s) P_{S}=\frac{\omega_{\mathrm{M}}(t)}{\omega_{\mathrm{s}}(t)} P_{S}(t), \\
& P_{S}(t)=-\frac{V_{s} L_{m}}{L_{s}} i_{r q}(t)
\end{aligned}
$$

where, $P_{S}$ is the power output in the stator side. Hence, as the wind turbine generates maximum power, the optimal power output in the stator side is defined as:

$$
P_{\text {smax }}(t)=\frac{\omega_{\mathrm{S}}(t)}{\omega_{\mathrm{M}}(t)} P_{M \max }(t)
$$

\section{SCHEME OF FREQUENCY STABILITY IN MICRO-GRID}

The micro-grid has two operation modes: the grid connected mode and the isolated mode. In the grid connected mode, the frequency in the micro-grid is retained by the power system. When the micro-grid is isolated from the power system, any active power imbalance between the consumption and generation leads to variations in the frequency and then, it can lead generators to shut down. Hence, the frequency retaining in the normal operation range is necessary. In this research, the micro-grid's rated frequency is $50 \mathrm{~Hz}$ and the normal operation range is between $49.8 \mathrm{~Hz}$ and $50.2 \mathrm{~Hz}$. This means that the proposed frequency adjustment method is to keep the frequency in the micro-grid in that range when the micro-grid operates in the isolated mode. This paper proposes two frequency control schemes for the DFIG wind turbine in a micro-grid operating in isolated mode. The first one is based on the power control of RSC and the second one is based on the rotor speed control of RSC. These schemes are named power control scheme and rotor speed control scheme, respectively. It is worth noting that these proposed schemes could apply in a quite small micro-grid without an energy storage system. In the case of a large network, the coordination of sources including distributed generators, storage systems, damping loads etc., and the scheme of shielding load should be considered.

\section{A. Power Control Scheme}

To retain the frequency of the micro-grid in the operation range, the reference power output of the wind turbine is calculated by the available power of the wind turbine and the error of the frequency, $\Delta f$. According to [7], to support the frequency control, the auxiliary signal comes from two components including the derivative of the actual frequency $d f / d t$ and the frequency error $\Delta f$. However, by using the derivative of the actual frequency, measurement noises will be multiplied and this can impact on the results. The frequency adjustment with the power control scheme is shown in Figure 3 . It is worth noting that this wind turbine operates in the two afore mentioned modes: connected to the power system and isolated mode. When the micro-grid operates in the power system connected mode, the wind turbine does not need to adjust the frequency so the reference power is designated by $P_{\text {smax }}$. When the micro-grid is disconnected from the power system, the wind turbine must support the diesel generator to adjust the micro-grid's frequency so the reference power output in the stator side of DFIG is described as in (14):

$$
\left\{\begin{aligned}
P_{s, r e f}(t) & =k_{1 P}(t) P_{\text {smax }}(t)+k_{2 P} \Delta f(t) \\
k_{3 P} P_{\text {smax }}(t) & =P_{\text {ref, min }} \leq P_{s, \text { ref }}(t) \leq P_{\text {smax }}(t)
\end{aligned}\right.
$$

where, $k_{1 P}$ is a deloading constant and it is always $k_{1 P}<$ $1, k_{2 P}$ is a droop coefficient, $k_{3 P}$ is a design constant, $\Delta f$ is the error of frequency, $\Delta f(t)=f_{\text {ref }}-f(t)$ which $f_{\text {ref }}$ is the reference frequency and $f$ is the actual frequency, and $P_{\text {smax }}$ is the maximum power output in the stator side.

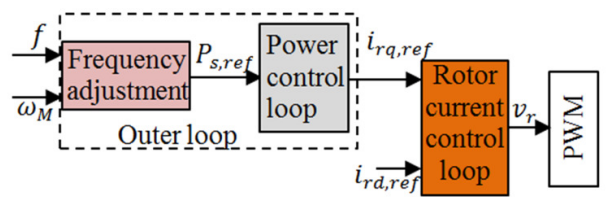

(b)

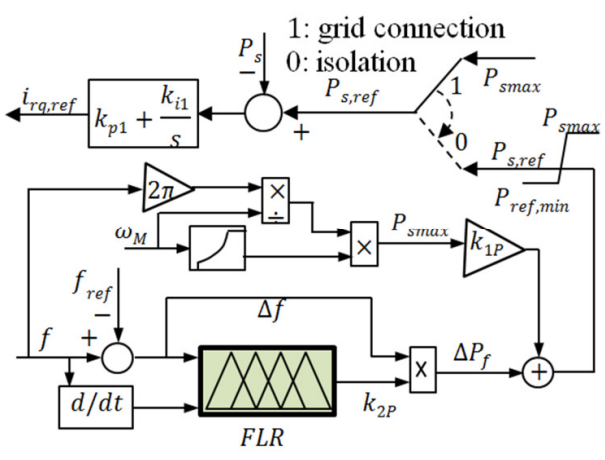

Fig. 3. Frequency adjustment with the power control scheme: (a) flowchart, and (b) outer loop.

To calculate $P_{\text {smax }}$, we use (13). Ideally, we calculate $P_{\text {Mmax }}$ from (3), however, in this research, we must use the feedback rotor speed and the MPPT curve from Figure 2(b). In this research, the droop coefficient is determined by a fuzzy logic rule (FLR) of two input signals including $\Delta f$ and the frequency deviation $d f / d t$.

The membership functions of the Fuzzy logic rule are shown in Figure 4 and Table I, where $\Delta f_{1}$, $\Delta f_{2}, \Delta f_{3}, d f_{1}, d f_{2}, a_{0}, a_{1}, a_{2}, a_{3}$ are design constants. The fuzzy rule is indicated in Table II. To obtain the above reference power, from (12), we must adjust the $i_{r q}$ component in the rotor side. Here, PI control is employed to make the error between actual power $P_{s}$ and $P_{s, r e f}$ become zero. The reference current $i_{\text {rq,ref }}$ is described by:

$$
i_{\text {rq, ref }}=k_{p 1}\left(P_{s, \text { ref }}-P_{s}\right)+k_{i 1} \int\left(P_{s, r e f}-P_{s}\right) d \tau
$$

where $k_{p 1}$ and $k_{i 1}$ are designed constants of the PI control. With this reference current, RSC must be controlled in a way that the actual current $i_{\text {rq }}$ reaches the reference value $i_{\text {rq,ref }}$.

TABLE I. TERMS OF FIGURE 3

\begin{tabular}{|c|c|c|c|}
\hline Symbol & Linguistic & Symbol & Linguistic \\
\hline NV & Very negative & De & Decrease \\
\hline N & Negative & IN & Increase \\
\hline Z & Zero & S & Small \\
\hline P & Positive & H & High \\
\hline VP & Very positive & & \\
\cline { 2 - 3 }
\end{tabular}


(a)

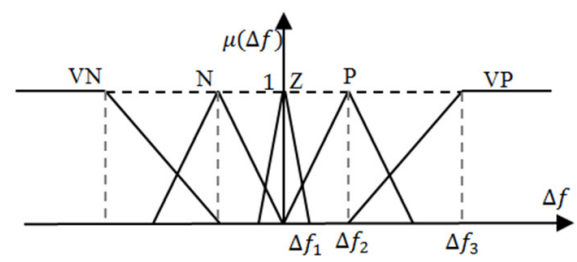

(b)

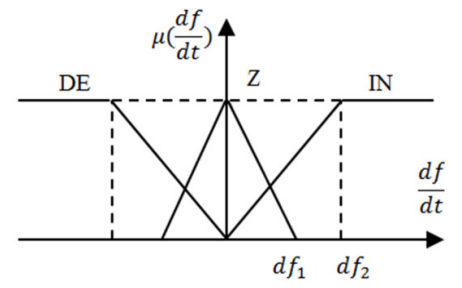

(c)

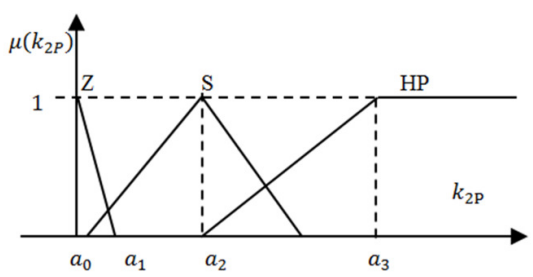

Fig. 4. The membership function of fuzzy logic: (a) Input $\Delta f$, (b) input $d f / d t$, and (c) output $k_{2 P}$

TABLE II. FUZZY RULES OF $k_{2 P}$

\begin{tabular}{|c|c|c|c|c|c|}
\hline df $/ d t \quad \Delta f$ & VN & $\mathbf{N}$ & $\mathbf{Z}$ & $\mathbf{P}$ & VP \\
\hline DE & $\mathrm{H}$ & $\mathrm{H}$ & $\mathrm{S}$ & $\mathrm{Z}$ & $\mathrm{S}$ \\
\hline $\mathbf{Z}$ & S & $\mathrm{S}$ & $Z$ & S & $\mathrm{H}$ \\
\hline IN & S & $\mathrm{Z}$ & $\mathrm{S}$ & $\mathrm{H}$ & $\mathrm{H}$ \\
\hline
\end{tabular}

\section{B. Rotor Speed Control Scheme}

By adjusting rotor speed, we can adjust the power output of the wind turbine, and hence, the wind turbine can control the frequency in the micro-grid by adjusting the rotor speed. From (10), we have:

$$
\omega_{M}(t)=(1-s(t)) \omega_{\mathrm{s}}(t)
$$

Clearly, when the micro-grid's frequency deviates amount of $\Delta f$, the rotational speed of the wind turbine varies:

$$
\Delta \omega_{M}(t)=(1-s(t)) \Delta \omega_{s}(t)=\frac{\omega_{M}(t)}{f(t)} \Delta f(t)
$$

To adjust the power output of the wind turbine, we can adjust the rotor speed. Hence, to adjust the frequency, we need to compensate this deviation. In this paper, the frequency adjustment using the rotor speed control scheme is indicated in Figure 5. The reference rotor speed when the wind turbine participates in the frequency adjustment in the micro-grid's isolation mode is described as:

$$
\left\{\begin{array}{c}
\omega_{M, r e f}(t)=k_{1 \omega}(t) \omega_{M o p t}(t)+k_{2 \omega} \Delta f(t) \\
\omega_{M o p t} \leq \omega_{M, r e f}(t) \leq \omega_{M \max }
\end{array}\right.
$$

where $k_{1 \omega}>1$ is a design constant, and $k_{2 \omega}$ is defined by the fuzzy logic rule, which is similar to Figure 4 and Table II.

Because the wind turbine is operated in the right side of the MPPT curve, the rotor speed is always over optimum speed. To avoid rotor speed increases to a too high values, the reference rotor speed $\omega_{M, r e f}$ should be limited between $\omega_{\text {Mopt }}$ and $\omega_{\text {Mmax }}$. Like the case of the power control scheme, the wind turbine will generate all available power as the micro-grid is connected to the power system. It means $\omega_{M, r e f}$ is equal to $\omega_{\text {Mopt }}$. When the micro-grid is isolated from the power system, the reference rotor speed is designated as in (18). To make the rotor speed $\omega_{M}$ approach its reference value, $\omega_{M, r e f}$, the rotor current in the $q$ axis must reach to its reference value which is determined by the error in the rotor speed and a PI control as:

$$
i_{\text {rq, ref }}=k_{p 2}\left(\omega_{M, r e f}-\omega_{M}\right)+k_{i 2} \int\left(\omega_{M, r e f}-\omega_{M}\right) d \tau
$$

where, $k_{p 2}$ and $k_{i 2}$ are designed constants of the PI control.

(a)

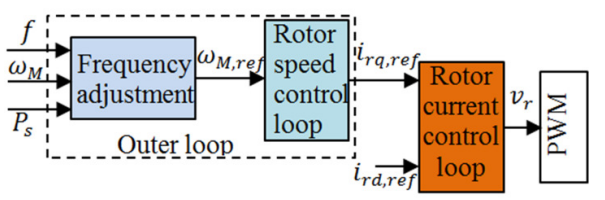

(b)

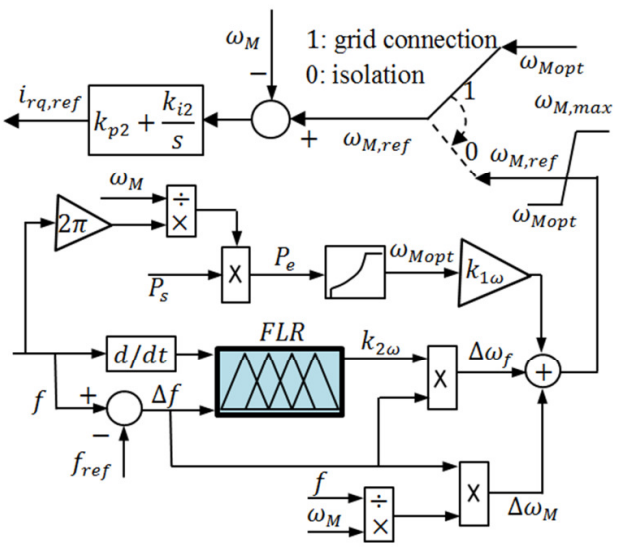

Fig. 5. Frequency adjustment with the rotor speed control scheme: (a) flowchart and (b) outer loop.

From this reference current, RSC must be controlled such that $e_{i q}=i_{r q, r e f}-i_{r q}$ approaches to zero. As can be seen from the two proposed schemes, a wind speed anemometer is not required. This is the difference from the method introduced in [10].

\section{RSC FOR CURRENT CONTROL}

Above we defined the reference current $i_{\text {rq,ref }}$. To support the frequency adjustment in the micro-grid, the actual current $i_{r q}$ must be satisfied $i_{r q, r e f}$. Here, we desire that:

$$
\boldsymbol{e}_{i}(t)=\left(\boldsymbol{i}_{r, r e f}(t)-\boldsymbol{i}_{r}(t)\right) \rightarrow 0
$$

where $\boldsymbol{i}_{r, r e f}=\left[\begin{array}{ll}\boldsymbol{i}_{r d, r e f} & \boldsymbol{i}_{r q, r e f}\end{array}\right]^{T}, \boldsymbol{i}_{r d, r e f}$ is designated by the voltage or reactive power control purpose.

From the state space equation of DFIG (7), we have:

$$
\boldsymbol{v}_{r}(t)=\boldsymbol{u}_{r}(t)+\Delta \boldsymbol{u}_{r}(t)
$$


where:

$$
\Delta \boldsymbol{u}_{r}=\left[\begin{array}{ll}
\Delta \boldsymbol{u}_{r d} & \Delta \boldsymbol{u}_{r q}
\end{array}\right]^{T}=\boldsymbol{B}_{r}^{-1} \boldsymbol{c}_{r}
$$

$\boldsymbol{u}_{r}=\left[\begin{array}{ll}\boldsymbol{u}_{r d} & \boldsymbol{u}_{r q}\end{array}\right]^{T}$ is a new control variable. Here, we employ PI controls to make the error $\boldsymbol{e}_{i}=\boldsymbol{i}_{r, \text { ref }}-\boldsymbol{i}_{r}$, so we have:

$$
\boldsymbol{u}_{r}(t)=\left[\begin{array}{lr}
k_{p 3} & 0 \\
0 & k_{p 4}
\end{array}\right] \boldsymbol{e}_{i}(t)+\left[\begin{array}{lr}
k_{i 3} & 0 \\
0 & k_{i 4}
\end{array}\right] \int \boldsymbol{e}_{i}(\tau) d \tau
$$

where $k_{p 3}, k_{p 4}, k_{i 3}, k_{i 4}$ are designed constants. By using (21), the rotor current can track their reference values. It means the active power/rotor speed is controlled and the wind turbine can support the frequency in the micro-grid.

\section{SimUlation RESUltS}

To evaluate and compare two frequency control schemes, we used Matlab/Simulink to simulate a micro-grid which is normally connected to a power system. This micro-grid consists of a DFIG wind turbine group of $4.5 \mathrm{MW}$, a diesel or a small hydro-power plant of 3.25MVA, and loads as shown in Figure 1. In these loads, Load 3 is a static load of 2.7MVA and the total power of the other loads is shown in Figure 6.

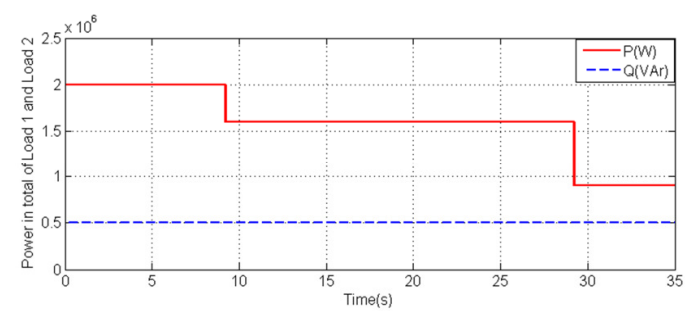

Fig. 6. The power load in total of Load 1 and Load 2.

We suppose that the micro-grid is isolated from the grid at $4 \mathrm{~s}$. It means before $4 \mathrm{~s}$, the micro-grid works in the grid connected mode and afterwards it operates in the isolated mode. The supposed wind speed is given in Figure 7. Simulation results are indicated in Figures 8-11. The parameters used for the fuzzy membership functions in FLR are defined in Table III.

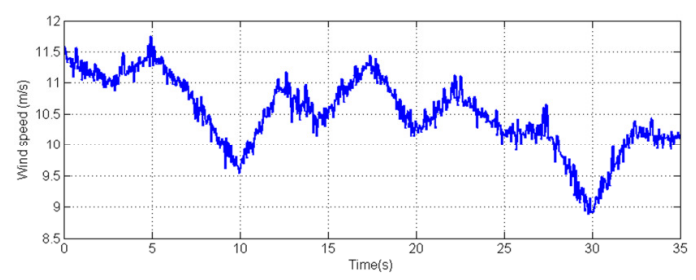

Fig. 7. Wind speed applied to the wind turbine.

As can be seen from Figure 8, before the $4 \mathrm{~s}$, the micro-grid is operating in the grid connected mode so the frequency in the micro-grid is almost constant. At the $4 \mathrm{~s}$, the micro-grid is disconnected from the power system and during a short transient interval $(4 s-7 s)$, the frequency is over the operation range. However, after this transient period, the frequency in the micro-grid with both schemes is retained and then it remains in the normal operation range, between $49.8 \mathrm{~Hz}$ and $50.2 \mathrm{~Hz}$. Note that at $9 \mathrm{~s}$ and $29 \mathrm{~s}$, the reduction of load makes the frequency increase rapidly but it still remains in the normal operation range. Comparing to the power control mode, the frequency in the micro-grid has more variation and the frequency error, $\Delta f=f_{\text {ref }}-f$, is higher.

TABLE III. THRESHOLD VALUES OF MEMBERSHIP FUNCTION

\begin{tabular}{|c|c|c|}
\hline Symbol & $\boldsymbol{k}_{\mathbf{2 P}}$ & $\boldsymbol{k}_{\mathbf{2} \boldsymbol{\omega}}$ \\
\hline$\Delta f_{1}$ & 0.0005 & 0.0005 \\
\hline$\Delta f_{2}$ & 0.001 & 0.001 \\
\hline$\Delta f_{3}$ & 0.005 & 0.005 \\
\hline$d f_{1}$ & 0.005 & 0.005 \\
\hline$d f_{2}$ & 0.015 & 0.015 \\
\hline$a_{0}$ & 20 & 5 \\
\hline$a_{1}$ & 25 & 10 \\
\hline$a_{2}$ & 60 & 80 \\
\hline$a_{3}$ & 125 & 150 \\
\hline
\end{tabular}

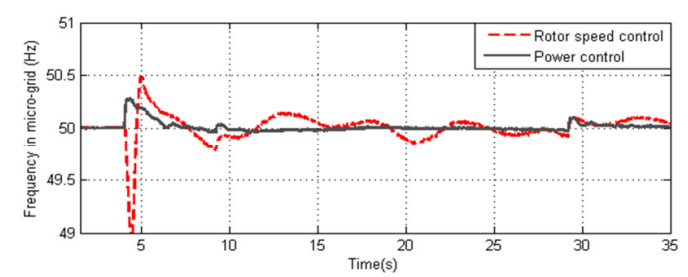

Fig. 8. Frequency in the micro-grid.

(a)

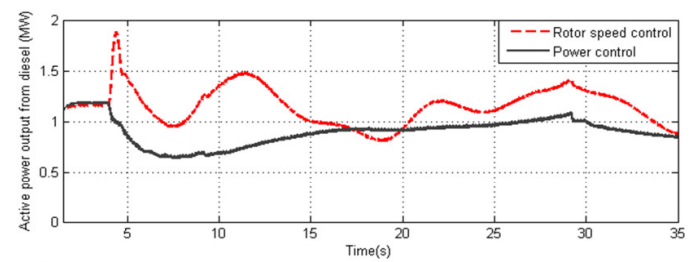

(b)

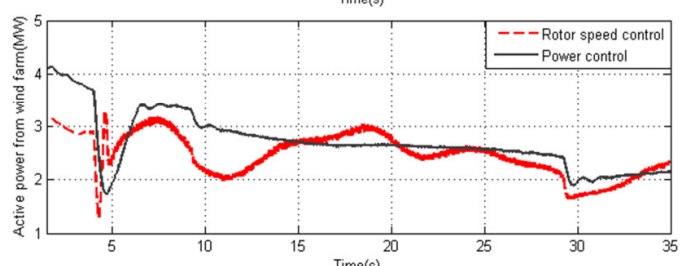

Fig. 9. The active power output from (a) the diesel and (b) the wind turbine group.

In terms of the active power output (Figure 9) we can see that with the rotor speed control scheme, the active power output generated from the wind farm has a significant fluctuation and hence, the power output of the diesel generator must vary. Comparing to the rotor speed control scheme, with the power control scheme the active power output of the wind farm is smoother and hence, the active power output of the diesel generator is also smoother. Concerning electrical energy, with the power control scheme the diesel generator only supplies around $8.5 \mathrm{kWh}$ during the simulation period while with the rotor speed control scheme it is around $10.9 \mathrm{kWh}$ as shown in Figure 10(a). The main reason for this is that with the power control the electrical energy extracted by the wind farm is higher than that with the rotor speed control, $27.2 \mathrm{kWh}$ and 
$24.8 \mathrm{kWh}$, respectively (Figure $10(\mathrm{~b})$ ). Figure 11 indicates that with the rotor speed control, the wind farm shared around $65 \%$ of the electricity demand in the micro-grid and the diesel generator supplies the rest. On the contrary, with power control the wind turbine shares around $70 \%$ of the demand. It means that with the power control scheme, we can save fuel cost comparing to the rotor speed control scheme.

(a)

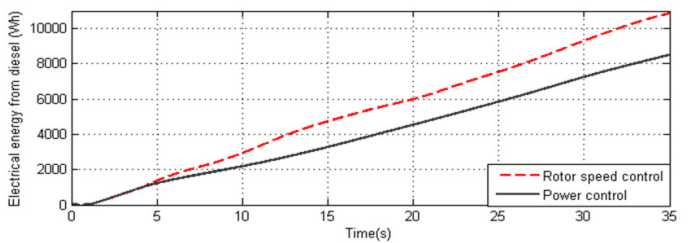

(b)

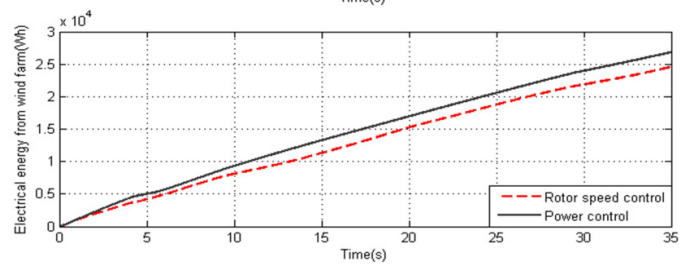

Fig. 10. The electrical energy from (a) the diesel and (b) the wind turbine group.
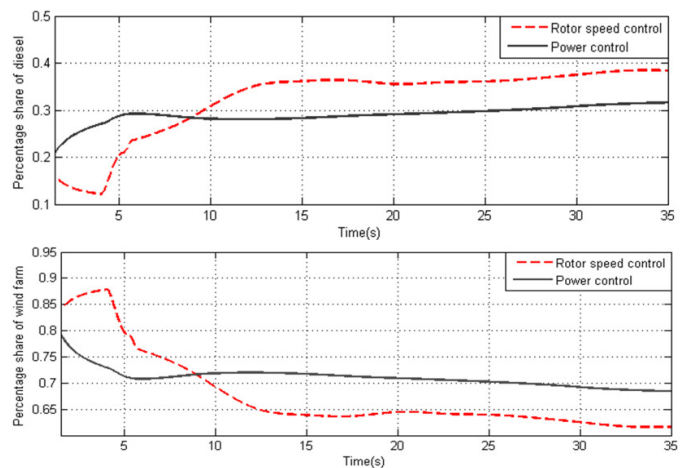

Fig. 11. The electrical energy sharing from (a) diesel and (b) wind turbine group.

\section{CONCLUSIONS}

This paper compared two schemes of frequency regulation applying to the DFIG wind turbine in the micro-grid. The first scheme is based on power control and the second one is developed by the rotor speed control. Simulation results indicate that with both schemes, the frequency in the microgrid remains in the operation range after the micro-grid is disconnected from the power system. However, the frequency in the micro-grid with power control is better than with rotor speed control. Additionally, with power control, the energy of the wind is utilized better than that with the rotor speed control.

\section{REFERENCES}

[1] Global Wind Energy Council, Global Wind Report 2017, GWEC, 2017

[2] R. G. Almeida, J. A. P. Lopes, "Primary frequency control participation provided by doubly fed induction wind generators", 15th Power Systems Computation Conference, Liege, Belgium, August 22-26, 2005

[3] K. Suzuki, A. Umemura, R. Takahashi, J. Tamura, N. Hino, "Frequency control of small power system with wind generators installed by using DFIG based diesel generator", 20th International Conference on
Electrical Machines and Systems, Sydney, Australia, August 11-14, 2017

[4] Y. Zhou, D. D. Nguyen, P. C. Kjaer, S. Saylors, "Connecting wind power plant with weak grid - Challenges and solutions", IEEE Power \& Energy Society General Meeting, Vancouver, Canada, July 21-25, 2013

[5] A. M. Howlader, N. Urasaki, A. Yona, T. Senjyu, A. Y. Saber, "A review of output power smoothing methods for wind energy conversion systems", Renewable and Sustainable Energy Reviews, Vol. 26, pp. 135146,2013

[6] D. G. Francisco, S. Andreas, G. B. Oriol, V. R. Roberto, "A review of energy storage technologies for wind power applications", Renewable and Sustainable Energy Reviews, Vol. 16, pp. 2154-2171, 2012

[7] Y. Xue, N. Tai, "Review of contribution to frequency control through variable speed wind turbine", Renewable Energy, Vol. 36, No. 6, pp. 1671-1677, 2011

[8] R. G. Almeida, J. A. P. Lopes, "Participation of doubly fed induction wind generators in system frequency regulation", IEEE Transactions on Power Systems, Vol. 22, No. 3, pp. 944-950, 2007

[9] M. El Mokadem, V. Courtecuisse, C. Saudemont, B. Robyns, J. Deuse, "Fuzzy logic supervisor-based primary frequency control experiments of a variable-speed wind generator", IEEE Transactions on Power Systems, Vol. 24, No. 1, pp. 407-417, 2009

[10] C. Pradhan, C. Narayan Bhende, "Enhancement in primary frequency regulation of wind generator using fuzzy-based control", Electric Power Components and Systems, Vol. 44, No. 15, pp. 1669-1682, 2016

[11] L. Fernandez, C. Garcia, F. Jurado, "Comparative study on the performance of control systems for doubly fed induction generator (DFIG) wind turbines operating with power regulation", Energy, Vol. 33, No. 9, pp. 1438-1452, 2008

[12] M. Garmroodi, G. Verbic, D. J. Hill, "Frequency support from wind turbine generators with a time variable droop characteristic", IEEE Transactions on Sustainable Energy, Vol. 99, No. 2, pp. 676-684, 2017

[13] M. K. Kim, "Optimal control and operation strategy for wind turbines contributing to grid primary frequency regulation", Applied Sciences, Vol. 7, No. 9, pp. 927-923, 2017

[14] A. R. Ardal, T. Undeland, K. Sharifabadi, "Voltage and frequency control in offshore wind turbines connected to isolated oil platform power systems", Energy Procedia, Vol. 24, pp. 229-236, 2012

[15] O. Rahat, I. Riazy, "Enhancing transient stability in limited variable speed induction generator (optislip) based wind turbine (case study: binalood wind farm)", Engineering, Technology \& Applied Science Research, Vol. 6, No. 6, pp. 1280-1287, 2016

[16] B. Wu, Y. Lang, N. Zargari, S. Kouro, Power Conversion and Control of Wind Energy System, John Wiley \& Sons, 2011

[17] R. Pena, J. C. Clare, G. M. Asher, "A doubly fed induction generator using back-to-back PWM converters supplying an isolated load from a variable speed wind turbine", IEE Proceedings-Electric Power Application, Vol. 143, No. 5, pp. 380-387, 1996

[18] A. B. Lajimi, S. A. Gholamian, M. Shahabi, "Modeling and control of a DFIG-based wind turbine during a grid voltage drop", Engineering, Technology \& Applied Science Research, Vol. 1, No. 5, pp. 121-125, 2011

[19] O. P. Bharti, R. K. Saket, S. K. Nagar, "Controller design of dfig based wind turbine by using evolutionary soft computational techniques", Engineering, Technology \& Applied Science Research, Vol. 7, No. 3, pp. 1732-1736, 2017

[20] D. C. Phan, S. Yamamoto, "Maximum energy output of a DFIG wind turbine using an improved mppt-curve method", Energies, Vol. 8, pp. $11718-11736,2015$ 